\title{
El enfrentamiento de la maternidad adolescente desde los márgenes
}

\section{Graciela Irma Climent*}

\author{
Nivel: Artículo \\ Fecha de recepción: 20 de julio de 2011 \\ Fecha de aprobación: 24 de agosto de 2011
}

\begin{abstract}
Resumen
Se analiza el impacto de las relaciones familiares en las estrategias con que las mujeres que fueron madres en la adolescencia enfrentan la maternidad y en la satisfacción con su situación vital. Se entrevistaron 40 mujeres que fueron madres en la adolescencia, residentes en una villa de emergencia de la ciudad de Buenos Aires, en 2008.

Las mujeres de familias no conflictivas tienen un mayor nivel educativo, mayor nivel de información sobre sexualidad, trabajan por elección y en empleos formales, pudieron formar y mantener una relación de pareja y controlar su fecundidad en mayor proporción que las mujeres de familias conflictivas. Las primeras tienen proyectos positivos para su futuro y se encuentran satisfechas con su situación vital mientras las segundas manifiestansentimientos detristeza, preocupación, aislamiento, soledad, no pueden proyectarse en el futuro y no están satisfechas con su situación vital.
\end{abstract}

Palabras clave: Enfrentamiento de la maternidad adolescente, Relaciones familiares, Estrategias de vida.

\begin{abstract}
This paper analyzes the impact of family relationships in the strategies of coping with maternity and in the satisfaction with their life condition of women who were adolescent mothers. We interviewed 40 women who had been adolescent mothers and who were living in a shantytown in Buenos Aires in 2008.

Women belonging to non problematic families have a better educational level, are more informed about sexuality, work because they choose to, hold a formal job, are able to engage in a sentimental relationship and to maintain it and to control their fertility in a greater proportion than women belonging to problematic families. The former have positive projects for their future, and are satisfied with their life condition, while the latter manifest feelings of sadness, concern, isolation, loneliness, cannot project into their future and are not satisfied with their life condition.
\end{abstract}

Key words: Coping with adolescent maternity, Family relationships, Life strategies.

* Licenciada en Sociología, Instituto de Investigaciones "Gino Germani", Facultad de Ciencias Sociales, UBA/Conicet. zycl@arnet.com.ar 


\section{Introducción}

Enfrentar la maternidad en la adolescencia, en especial si no ha sido planeada, es un desafío para la joven mujer. En ese complejo proceso las adolescentes siguen diversas trayectorias poniendo en juego recursos personales, sociales, materiales y desplegando diversas estrategias. Contar con el apoyo parental y familiar va a ser fundamental para el enfrentamiento de la maternidad. De ahí la importancia, desde una perspectiva psicosocial que toma en cuenta los procesos interactivos, que se confiere a la calidad de las relaciones en la familia primaria, armónicas o conflictivas, que conformarán un clima familiar más o menos propicio para dicho enfrentamiento.

Pero los diferentes contextos de socialización según residencia urbana o rural o en sectores socioeconómicos bajos, medios o altos, proveen diferentes estructuras de oportunidades que dan lugar a diversas maneras de vivir la "adolescencia", la "juventud" y también la "maternidad".

Uno de los fines de la investigación es la de producir la información necesaria para que las políticas sociales lleguen con sus acciones y programas a los distintos sujetos y grupos poblacionales. De ahí que es preciso reconocer la heterogeneidad de las "maternidades adolescentes" para identificar aquellas que requieren particular atención por parte de las políticas públicas.

Por otra parte, el embarazo adolescente ha sido estudiado con distintos enfoques. La mayoría de los autores consultados se centran en el análisis del contexto socio-económico y familiar. Describen factores sociales asociados con dicho embarazo como la pobreza, el nivel educacional, la educación sexual recibida y el impacto de los medios de comunicación.

Por otro lado, las investigaciones sobre el tema que abordan la dimensión subjetiva en relación al embarazo adolescente, han puesto en evidencia la forma en que el contexto socioeconómico y cultural determina diferencialmente el marco valorativo en el 
que se encuadran los comportamientos sexuales y reproductivos. Por ejemplo, a partir de la década del 90 varias investigaciones realizadas en Argentina se han centrado en variables como las representaciones sociales de género, demostrando que éstas difieren de un estrato social a otro y se hallan relacionadas con los niveles educativos. Se encontró que aunque la mayoría de las adolescentes anhela la maternidad, para las del estrato medio y alto constituye un proyecto a largo plazo que compite con otros como estudiar o trabajar, mientras que para las del estrato bajo constituye casi el único proyecto, a corto plazo. Acorde a la socialización de género tradicional de estas últimas adolescentes el trabajo y el estudio son necesidades de segundo orden, supeditadas a la asunción del rol materno y conyugal.

A la vez, en las adolescentes del estrato bajo predominan las representaciones sociales tradicionales sobre los roles sexuales, lo que se traduce en relaciones asimétricas de pareja que inciden en la negociación del uso de métodos anticonceptivos, los que a menudo derivan en relaciones sexuales no protegidas y en embarazos inoportunos (Infesta Domínguez, 1993; Pantelides, Geldstein e Infesta Domínguez, 1995; Climent y Arias 1996, Gogna, 2005).

Por otra parte casi todos los estudios realizados abordan el tema de la familia pero tienden a concentrarse en aspectos relacionados con la composición familiar -niñas criadas en familias monoparentales, familias numerosas, instituciones- y a partir de ellos se hacen inferencia sobre la dinámica de la familia y la calidad de las relaciones familiares (Pantelides, Geldstein e Infesta Domínguez, 1995; Piñero, 1998; Palma, 1991; Climent y Arias, 1996; Mendieta Cruz et al., 1996).

Menos estudiado ha sido el tema del enfrentamiento de la maternidad en la adolescencia, es decir, el modo en que las adolescentes afrontaron su vida cotidiana a partir del nacimiento de su hijo/a. Y si bien ha sido reconocido el impacto de la pobreza en la maternidad (Climent, Arias y Spurio, 2000), no se ha profundizado en las relaciones familiares armónicas o conflictivas, 
las que dan lugar a una heterogeneidad de "maternidades adolescentes".

En el presente escrito se intenta hacer un aporte desde la perspectiva de género y del enfoque de ciudadanías diferenciadas, los que permiten captar las diferencias socioculturales de diversos grupos con sus necesidades y derechos específicos para identificar los que requieren particular atención por parte de las políticas públicas (Di Marco, 2005; Ortale, 2009). En este caso, nos centramos en los de las mujeres - adolescentes y jóvenes - madres- pobres - de familias conflictivas.

\section{Objetivo y metodología}

El objetivo de este artículo $^{1}$ es describir la calidad de las relaciones familiares en la familia primaria y relacionarla con: 1) las distintas estrategias -en especial las educacionales, laborales, conyugales, reproductivas- desplegadas por las mujeres que fueron madres en la adolescencia, y 2) con la evaluación que dichas mujeres hacen de su situación vital actual, reflejando su nivel de bienestar. Con ese objetivo, en 2008 se entrevistaron 40 mujeres que habían sido madres en la adolescencia -antes de los 20 años- y cuyo primer hijo tuviera entre 1 y 10 años, y fuere atendido en el Centro de Salud y Acción Comunitaria n 8, del Gobierno de la Ciudad Autónoma de Buenos Aires, ubicado en la Villa de Emergencia 21-24 del barrio de Barracas².

1 Basado en la investigación Oportunidades y riesgos en el enfrentamiento de la maternidad en la adolescencia llevada a cabo en el Instituto de Investigaciones "Gino Germani", Facultad de Ciencias Sociales, Universidad de Buenos Aires/ CONICET. 2 Diecisiete de las entrevistadas nacieron en la Capital Federal o el Gran Buenos Aires -casi todas vivieron siempre en la villa-, 5 nacieron en provincias argentinas y 18 en países en limítrofes ( 15 de Paraguay, 2 de Bolivia y 1 de Uruguay). La mayoría de las migrantes reside en la villa desde hace menos de 6 años y provienen de zonas rurales o semiurbanas.

Actualmente 10 mujeres tienen entre 16 y 19 años, 16 tienen entre 20 y 24 años y 14 entre 25 y 30 años, siendo el promedio de edad de 22,9 años. La mayoría de ellas (27) está unida o casada, 9 están separadas y 4 son solteras. 


\section{Recursos y estrategias}

En el transcurso de la vida cotidiana las personas deben enfrentar diversas situaciones que pueden considerarse críticas por los cambios que implican, como la maternidad en la adolescencia. Con el nacimiento de un hijo deben asumir nuevos roles y tareas, reestructurar relaciones y acuerdos, aparecen nuevas necesidades económicas y de vivienda. La crianza y el cuidado del hijo, el sostén afectivo y económico que requieren, la adaptación a una pareja generalmente reciente, son exigencias que se le presentan a la adolescente junto a otras como su desarrollo personal y laboral.

Para enfrentar dichas situaciones críticas las personas cuentan con diversos recursos personales y sociales que se ponen en juego junto a los recursos materiales (Díaz Veiga, 1987; Pearlin et al., 1981). Dentro de los recursos personales se considerarán las representaciones sociales de género que se evidencian en las prácticas reproductivas y sexuales y en los proyectos de vida; el nivel educacional alcanzado como indicador de los aprendizajes escolares adquiridos, y el conocimiento acerca de la sexualidad.

Los recursos sociales están constituidos por las redes familiares y comunitarias formadas por parientes, amigos, vecinos e instituciones que proveen apoyo de diferentes formas: emocional, instrumental e informacional, o cognitivo (Díaz Veiga, 1987). Pero la mera relación con familiares, vecinos o instituciones no es suficiente. Es la calidad de esas relaciones lo que hace que ese apoyo pueda concretarse y ser efectivo (Horwitz, 1991).

Las estrategias de vida se refieren a la forma en que las mujeres se organizan para satisfacer sus necesidades cotidianas, interesando las estrategias desplegadas a partir del nacimiento del hijo en relación a las prácticas sexuales y reproductivas, formación de parejas, crianza de los hijos, vivienda, educación, trabajo, sostén económico, etc.

Estas estrategias no son necesariamente planificadas en base a criterios racionales sino que se van implementando como res- 
puestas a las necesidades cotidianas, a los recursos disponibles y a las posibilidades del medio (Torrado, 1992; Feijóo, 1993). A veces se implementan estrategias de "emergencia" para paliar situaciones inesperadas -desempleo, enfermedades, abandono de la pareja-. Otras, por la gravedad de la situación y la falta de recursos, parece que más que "opciones" son "imposiciones" del "destino" (Fernández, 1994). Además, las estrategias de vida están atravesadas por los condicionantes de género. Trabajar o no trabajar, usar o no anticonceptivos, separarse o mantener relaciones conyugales conflictivas dependerá de las relaciones de poder al interior de las parejas, la valoración de la maternidad o los roles asignados a la mujer (Climent, Arias y Spurio, 2000).

\section{Transformaciones en las relaciones familiares}

Para hablar de las relaciones familiares es preciso enmarcarlas en el proceso de transformación de la institución familiar que se ha dado en las seis o siete últimas décadas. La incorporación masiva de la mujer al Mercado de Trabajo y la difusión del uso de los métodos anticonceptivos permitieron que las mujeres alcanzaran una mayor independencia. Con ello se fue debilitando el modelo de familia "patriarcal", dando lugar a una relativa democratización de su estructura de poder y de las relaciones de género. Pero este proceso dio lugar a los conflictos por el cuestionamiento a la autoridad paterna y por la redefinición de la posición subordinada de la mujer y los hijos. A la vez, las mujeres fueron tomando conciencia de la desigualdad y de sus derechos (Jelín, 2005; Climent, 2005).

Pero no todas las mujeres pueden gozar de sus derechos. Las mujeres pobres encuentran más dificultades para desarrollar un proyecto vital autónomo y de gozar de esos derechos debido a su menor acceso a la educación: con sus saberes reducidos a las tareas domésticas y al cuidado de niños, el desarrollo de la autonomía y la autoestima y la posibilidad de acceder al mercado de trabajo se verán afectados (De la Vega, s/f). Esa reclusión en el 
ámbito doméstico lleva al aislamiento social, lo cual dificulta la integración social al afectar los dos ejes de la misma, la inserción laboral y relacional (Castel, 2004). Y justamente, varios autores han constatado que, en nuestro país, la mayoría de las madres adolescentes son pobres. Uno de cada seis niños nace de una madre adolescente y más del $80 \%$ de esas madres se ubica en los dos primeros quintiles de ingreso per cápita, es decir: en los sectores sociales más pobres (Lupica y Cogliandro, 2007; Pantelides y Binstock, 2007, Gogna, 2005, Climent, 2003; Urresti, 2000).

Si bien son varios los derechos de las mujeres, niñas, niños y adolescentes que han sido incorporados a nuestra Constitución -sobre derechos reproductivos y sexuales, violencia familiar, patria potestad compartida, etc.-, cabe preguntarse cómo se respetan esos derechos en el ámbito familiar, en el que su vulneración no es fácilmente visible.

\section{Familia y relaciones de amor y poder}

En nuestra sociedad, una de las expectativas sociales es que los vínculos familiares estén basados en el afecto y el cuidado mutuo. Pero si bien sus miembros están ligados por tareas e intereses colectivos, también tienen intereses propios diferenciados (Jelín, 2005) que pueden ser fuente de conflictos.

La familia está atravesada por relaciones de poder asimétricas según género y generación al concentrarse el poder en un polo de la relación: en los padres en relación a los hijos, en el marido en relación a la mujer. Por ende implican relaciones de desigualdad (Caldeiro, 2005). Cuando el poder deriva de la capacidad de coacción se ejerce de manera violenta en sus diversas formas: física, verbal, psicológica, sexual, económica, y siempre implica una grave violación a los derechos humanos.

Pero, si bien la familia es considerada el lugar del afecto y el cuidado, al ser también el lugar de la intimidad y de lo privado se convierte en un ámbito privilegiado para el ejercicio de la vio- 
lencia fuera de la presencia de testigos, por lo cual, a menudo, permanece oculta $y$, por ende, impune.

La violencia familiar, que en la mayoría de los casos se dirige hacia las mujeres en la relación conyugal y a las niñas y a los niños en la relación filial, reconoce un mismo origen: las relaciones desiguales de poder enraizadas en la cultura patriarcal. En estos casos se trata del ejercicio del "poder sobre" que implica necesidad de apoderamiento y sometimiento del otro, ejercicio que está al servicio de uno mismo y de mantener el propio status (Ricón, 2010).

El ejercicio del "poder sobre" da origen a resentimientos y reproches y a sentimientos de abandono y soledad. La imposición del poder por parte de los padres mediante amenazas, órdenes arbitrarias, golpes y castigos diversos, sólo promueve la obediencia basada en el miedo al castigo. Por el contrario, el "poder para", el ejercicio de la autoridad mediante el diálogo y la toma de decisiones por consenso, conduce a que los hijos aprendan a vivir en un ambiente democrático de respeto mutuo.

Si bien en la familia se reproducen la desigualdad y el autoritarismo también es posible el cuestionamiento, la expresión de desacuerdos y la modificación de las normas. Por eso, en ella pueden darse procesos de democratización de las relaciones familiares lo que la convierte en un ámbito privilegiado de aprendizaje de los derechos humanos (Di Marco, 2005; Caldeiro, 2005).

\section{Las relaciones familiares y situación vital}

Según el funcionamiento familiar -armónico o disarmónico- la familia puede ser un factor protector que genera bienestar y comportamientos saludables o un factor de riesgo que genera malestar y comportamientos no saludables (Weinreich e Hidalgo, 2004; Rodrigo, Máiquez, García et al., 2004).

Diversas investigaciones demostraron una fuerte correlación entre conflictividad familiar y conductas de riesgo en los adoles- 
centes, y que las familias en las que se dan conflictos de pareja son más vulnerables a presentar problemas de violencia intrafamiliar, abuso y dependencia de drogas y alcohol, abuso sexual, pertenencia a grupos violentos o sectas religiosas (Florenzano, Sotomayor y Otava, 2001). Además, la inclusión de los hijos en dinámicas conflictivas de los padres, se asocia con el sufrimiento de los hijos que se acentúa si dicha inclusión se combina con una escasa parentalidad-ausencia material o simbólica de uno o de ambos padres, ausencia de normas en la educación de los hijos, falta de cuidado de los mismos e indiferencia afectiva.

Un clima familiar donde la violencia doméstica y los conflictos paterno-filiales son permanentes o donde falta la autoridad para normar, produce una desestabilización en los adolescentes. La evitación, el abandono, la separación, son la antítesis de la cohesión familiar y suponen amenazas profundas para el mantenimiento de las relaciones familiares, dando origen a conductas antisociales.

Por el contrario, los vínculos afectivos positivos y particularmente el efecto que produce en el desarrollo de los sujetos contar con padres "bien avenidos" contribuyen al desarrollo de un sentido de la vida y de una conciencia ética ya que los hijos los toman como referentes y adoptan sus valores y normas si mantienen una relación afectiva positiva con ellos (Gubbins, Venegas y Romero, 1999).

Por otra parte, la calidad de las relaciones familiares se vincula a los comportamientos reproductivos "de riesgo" que dan origen a los embarazos en la adolescencia. Se ha demostrado que el embarazo adolescente está asociado a relaciones familiares conflictivas y a las dificultades de comunicación entre padres e hijas/os dado que las relaciones conflictivas afectan la posibilidad de dar información y formación sobre la sexualidad a los hijos e hijas e influye en la aceptación de las pautas familiares al respecto (Mendieta Cruz, 1996; Geldstein, Infesta Domínguez y Delpino, 1996; Climent, 2009). 
Por otra parte, la teoría del apego sostiene la importancia de establecer vínculos de apego seguro entre padres e hijos para el adecuado desarrollo de los últimos (Bowbly, 1989), ya que promueven vínculos interpersonales positivos en el futuro, un fuerte sentimiento de seguridad, la autoestima y la capacidad de afrontamiento en situaciones de crisis. Por el contrario, la abdicación parental -padres que abandonan su función por fallecimiento, abandono de los hijos, alcoholismo, etc.- deriva en hijos con sentimientos de pérdida, ansiedad, aislamiento y soledad y con tendencia a una búsqueda compulsiva de otros proveedores de la relación de afecto necesitada (Large, 1989; Louro Bernal, 2005).

La calidad de las relaciones familiares se estableció considerando cómo fue la relación entre los padres, de la madre con la hija y del padre o padrastro con la hija durante la mayor parte de la vida de la entrevistada hasta que se unió, se embarazó o se fue de la casa.

La satisfacción con la situación vital se refiere a la valoración que la persona hace de diversos aspectos de su vida -familia, estudios, trabajo, salud, amigos, tiempo libre- (Moyano Díaz y Alvarado, 2007). Se consideró la evaluación de la entrevistada sobre su satisfacción vital y los motivos de la misma, las manifestaciones de tristeza, alegría, preocupación, esperanza, aburrimiento, soledad, así como sus planes vitales y la necesidad de cambios.

\section{Los testimonios}

Se presentarán los testimonios de tres mujeres de familias con diversas características relacionales. ${ }^{3}$

ELIZA, 18 años, vivió siempre en la villa de emergencia. Vive con la pareja (18 años), el hijo de 10 meses, la madre, el padrastro y 3 hermanos menores. Tiene 2 hermanos mayores, hijos de la

\footnotetext{
3 Las palabras de las entrevistadas se presentan en letra cursiva.
} 
primera pareja de la madre. Ella es hija de esa pareja. El padre falleció hace 8 años, estando ya separado de la madre y cuando ésta ya vivía con su actual marido. Su pareja cursó estudios primarios completos y trabaja en una parrilla. La madre es camarera en un colegio y el padrastro es operario de una empresa de limpieza urbana. La casa es propia, de material, de 4 habitaciones.

Eliza se crió en una familia en las que predominaban las relaciones familiares armónicas. Con los padres antes había discusiones porque a veces no les hacía caso cuando me decían que venga temprano o si no me dejaban salir y yo salía; no sé, la adolescencia era así. Me retaban, me decían que no iba a salir pero después me dejaban. Ambos padres ponían las normas: Vení temprano, cuídate. Respecto a tareas domésticas yo siempre hacía todo, no me tenían que decir nada, yo sabía lo que tenía que hacer. De su padrastro dice: Él me crió de chiquita, nos llevamos siempre bien.

Se lleva bien con su pareja; a veces discuten por el bebé. No hay cosas que él no le deje hacer. Yo antes no lo dejaba salir a bailar pero ahora sí porque si lo tenés muy, muy se te va a ir. Yo también a veces voy a bailar con mi cuñada y él se queda a cuidar al nene.

No tiene amigas y si quiere hablar de sus cosas personales puede hacerlo con la cuñada. En esos casos no recurre a la madre pero sí ante algún problema con el hijo, así como también con la suegra. A todos ellos y al padre puede recurrir si tiene un problema económico.

Respecto a las estrategias educacionales dice: Ahora empiezo 5to. del secundario otra vez porque yo abandoné 2 veces: una porque ya estaba por tener y después no quise ir más por el bebé, era muy chiquito, y otra porque se enfermó. Pero tengo que terminar, quiero terminar. $Y$ ahora voy a empezar también a la noche pero ahí son tres horas. Antes eran 4 horas y media y venía retarde, a las 12.

En cuanto a las estrategias conyugales, sexuales y reproductivas refiere que estuvo de novia dos años con su actual pareja, con la que se inició sexualmente. Se unieron cuando ambos te- 
nían 16 años. Los padres de ambos estaban de acuerdo. Sabía que podía cuidarse para no quedar embarazada: Mi mamá me había dicho que me tenía que cuidar con preservativo y que vaya y pida en la salita. Un tiempo usó preservativos. Luego cambió por las pastillas porque a veces ya no usábamos preservativo y por ahí quedaba embarazada. Al año de la unión se embarazó. Yo tomaba pastillas y me olvidé de tomar una semana y quedé embarazada. Desde hace 3 meses volvió a tomar pastillas.

De la organización de la vida cotidiana dice: Mi mamá trabaja y yo lo llevo a mi nene con la abuela (paterna) porque no me deja hacer nada y vuelvo y ordeno la casa, lavo y después lo voy a buscar.

Los padres colaboran con el sostén económico: Mi mamá y mi papá me dijeron que para comer no me va a faltar nada pero que mi marido me tiene que vestir a mí y a mi nene. Las cosas del colegio mi marido me tiene que comprar.

De la crianza del hijo comenta: El nene no me deja hacer nada, se pega mucho a mí. Con el papá está un rato y ya quiere venir conmigo y con la abuela también se queda. Lo dejará con ella cuando vaya a la escuela. Lo hace controlar todos los meses; por cualquier cosa lo llevo al hospital. El marido también se ocupa de los cuidados del hijo: De todo; cambiarlo no, no sabe, le da de comer, me ayuda a bañarlo y cuando tengo que hacer algunas cosas me lo tiene un rato.

Sus representaciones sociales de género oscilan entre las tradicionales y las modernas: Considera que es preferible que la mujer se ocupe de la casa porque vendría a ser que los hombres no saben hacer algunas cosas o no les gusta y a las mujeres sí. Bah, a mí me gustan, a otras no sé. Pero el hombre tiene que colaborar, tiene que ayudar a hacer las cosas.

Tiene diversos proyectos que parecen realistas. Por ahora no quiero más chicos. Cuando tenga mi casa sí pero primero voy a terminar la escuela, a empezar a trabajar y tengo que empezar a hacer mi casa. Quisiera trabajar en cualquier cosa. Al nene lo podría dejar con mi suegra. Pero ahora no se consigue mucho. Yo quería hacer muchas cosas, 
ser policía, pero ahora ya no, tengo a mi hijo. También se me ocurrió enfermería o contador público. Voy a averiguar en la escuela; ahí te dicen.

Está relativamente satisfecha con su situación vital actual: Muchas veces se siente aburrida porque ya terminé de hacer todo y no sé qué hacer. Sin embargo no está cansada de hacer siempre lo mismo, porque me gusta hacer lo que hago, me encanta limpiar. A veces se siente triste porque no sé, puede ser porque no tengo trabajo, me anoto en muchos trabajos pero no consigo. Con su vida está poco satisfecha porque no tengo trabajo, por otra cosa no, estoy bien.

En síntesis, Eliza se crió en una familia con relaciones armónicas, que a pesar de su condición de pobreza parece integrada, en los términos de Castel. Esta familia le ha dado y le da apoyo económico y un relativo apoyo emocional. Actualmente también cuenta con el apoyo instrumental de su suegra. Se observa una fuerte determinación para concluir sus estudios. Su embarazo, no planeado, se debió a un "olvido". No tiene problemas en la crianza de su hijo, que comparte con su marido, con quien mantiene relaciones de igualdad. Puede proyectarse en el futuro -seguir estudiando, trabajar, hacer su casa-, se siente relativamente satisfecha con su vida y lo que más le preocupa es no encontrar trabajo.

MARCELA, 20 años, vive en la villa desde que nació. Actualmente vive con la menor de las hijas, de 4 años, la hermana de 22, tres sobrinos de 7, 6 y 1 años y el padre de 58 años -dueño de la casa, que no trabaja porque no quiere-. Tuvo a su primera hija -de 6 años, que no vive con ella- a los 14 años.

Se crió en una familia con relaciones familiares entre conflictivas y abandonadas: Mi mamá nos abandonó cuando éramos chicas; no la conozco. Cuando era chica es como que mi papá no me prestaba mucha atención, que no le importaba mucho lo que yo hacía de mi vida. Ahora vivimos peleando, por los chicos, por todo. Tampoco cuenta con un adecuado apoyo emocional. A veces charla con una vecina, alguna que otra de mis cuñadas, compañeras de trabajo. Pero hay cosas que no se las comento a nadie porque amigas hoy en día no hay, conocidas sí. 
En cuanto a sus estrategias educativas y laborales refiere: Hice 4to. Grado, repetí 2 veces y después ya no fui más; no me gustaba. Yo no iba porque mi papá era un hombre que no me exigía y como él no me decía "hacé esto" y lo tenía que hacer, yo hacía si yo quería y en ese tiempo me agarró ganas de dejar la escuela y la dejé. Actualmente trabaja en una empresa de limpieza de 18 a 22.

De sus estrategias sexuales y reproductivas dice que quedó embarazada a los 13 años. En ese entonces no hacía nada, estaba en mi casa, estaba de novia. Era su primer novio -que tenía 16 años-, con el que se inició sexualmente. No quería quedar embarazada.

Su información sobre la posibilidad de embarazarse era escasa: Si sabía es por lo que oía pero mucho no entendía porque no me hablaba nadie a mí; como nunca tuve una charla de madre, nunca una tía o mi papá me decía que tenía que cuidarme.

Con el papá de mis hijas no usaba preservativo; a él no le gustaba. Ahora hace tres meses estoy saliendo con otro pero no estoy muy segura porque por ahí se pone el preservativo o como que no le importa mucho y prefiero tomar yo la pastilla. Después que tuve a la primera me habían dicho de tomarlas pero como él no quería, no me dejaba salir a ningún lado ni podía comprarlas... Tuvo dos abortos: Este segundo busqué perderlo; no lo quería.

De sus estrategias conyugales y residenciales relata: Cuando quedé embarazada nos juntamos en la casa de mi suegra, al lado de lo de mi papá. Con la suegra se llevaba mal. Después volví a mi casa. Nos separamos muchas veces porque él me pegaba desde que estaba embarazada. Y al añito que cumplió mi hija, quedé embarazada de vuelta... Ahora mi ex marido está preso por robo. Él, antes, ya estuvo preso, salió y yo estuve con él una semana y como veía que la relación no iba volvimos a separarnos y como él no aceptaba eso, no me dejaba salir a trabajar, me quería pegar, me fui a lo de una amiga y cuando cayó preso volví a mi casa y así estoy, cuando él sale me voy, cuando cae vuelvo.

Tiene dificultades en la crianza de las hijas: A la más chiquita la tengo yo. La mayor vive con la abuela; la crió desde que nació. Con 
este arreglo está en parte conforme porque yo antes no trabajaba y no tenía nada para darle. Ahora trabajo pero tampoco mi sueldo es mucho como para decir "le voy a dar todo a mi hija"; y en parte no, porque a veces no me la dejan ver, depende de cómo estén ellos de ánimo y los fines de semana venir a dormir conmigo no siempre la dejan. La hija mayor concurre a primer grado. La menor no está escolarizada: Estaba yendo a jardin de infantes pero la saqué porque me fui a vivir a lo de mi compañera porque él salió de la cárcel y no me deja en paz. Cuando cayó preso otra vez yo volví y cuando quise que la vuelvan a meter en el jardín, no la aceptaron y ahora no encuentro vacante en ningún lado. Las hijas sólo tuvieron fiebre, resfríos. Ahora hace rato que tendría que llevarla a la menor porque está muy flaquita. Las dos hijas concurren a un comedor comunitario.

Su vida cotidiana gira alrededor del trabajo y de las tareas domésticas, el cuidado de la hija y los sobrinos que comparte con la hermana al igual que los gastos.

En cuanto a sus representaciones sociales de género sostiene que es preferible que si la mujer puede trabaje afuera, porque en la casa tienen que ayudar los dos y no solamente una; no es justo y es mejor para tener mejor trato con la pareja porque hay algunos hombres que piensan que las mujeres son sirvientas, que tienen que tener todo hecho porque él trabaja.

No puede formular proyectos para el futuro: Ninguno, no hago planes para mi vida. Tampoco hace planes respecto a su novio: No veo futuro con él. Bah, como novio sí, pero como pareja no, porque él es un pibe que tiene 21 años, no tiene hijos, y yo ya tengo dos. Él es el nene de la casa, no trabaja, siempre que necesita algo se lo pide a la mamá, zapatillas, ropa, todo. En el futuro se ve igual que ahora, sola, esperando salir adelante... Con la ayuda de nadie, con la mía, trabajando, como siempre.

En relación a su situación vital actual dice que hubiera querido tener su primera hija después de los 20; así hubiera podido terminar mi escuela, hacer cosas de chicos y no andar criando hijos. Muchas veces se siente triste por muchas cosas, me pongo mal, me deprimo, 
soy así, no sé por qué; por no tener mi casa propia, por mi hija que no vive conmigo. Está poco satisfecha con su vida.

Marcela vivió en una familia poco contenedora, con un padre que no ponía normas y se desentendía de su crianza. Su educación sexual fue muy escasa y se embarazó, sin planearlo, a los 13 años. No pudo negociar con su pareja el uso de anticonceptivos. Así tuvo 4 embarazos y 2 abortos. La pareja la maltrataba y se separó reiteradamente. Él estuvo preso en varias oportunidades, circunstancias que incidieron en sus estrategias laborales, residenciales y de crianza de las hijas. La mayor no vive con ella, la menor no está escolarizada y está con bajo peso y ambas concurren a un comedor comunitario. Actualmente trabaja con un sueldo bajo. Su experiencia conyugal, caracterizada por relaciones de género violentas y desiguales, la ha llevado a valorar las relaciones en las que predomine la igualdad. Ha "aprendido" la importancia de "cuidarse" y no confía en que su actual pareja lo haga. No tiene vínculos de amistad con personas que pudieran darle apoyo emocional. Cuenta con apoyo instrumental por parte de la hermana -cuidado de la hija, compartir tareas domésticas y gastos-. En ella predominan sentimientos de abandono -ligados a la ausencia de la madre y a la relación entre conflictiva e indiferente con el padre-, se siente desesperanzada, sin poder contar con la ayuda de nadie y no puede hacer proyectos para el futuro. No está satisfecha con su vida.

TAMARA, 19 años. Vive en la villa desde que nació. Tuvo a su primer hijo -hoy de 3 años- a los 15. Vive con la madre, el hijo y 6 hermanos. En total somos 11. La vivienda es propia, de material. La madre, de 45 años, no trabaja aunque lo hizo anteriormente en servicio doméstico. Cobra la tarjeta de la ciudadanía porteña y tiene la pensión de madre de 7 hijos. Respecto al padre dice: No vive con nosotros. Mi papá es mío solo, después los demás tienen otros padres. Somos de tres papás distintos.

Se crió en una familia con relaciones familiares conflictivas. Las relaciones con la madre son difíciles: Con ella no hablo, no le 
cuento nada, no sabe nada de mi vida. Critica todo lo que hago; si salgo, si no salgo, si hago algo en mi casa o si no lo hago; todo. Si los hijos hacen algo que está mal, la madre se pone reloca, grita. A ella le habían sacado a mis 5 hermanos más chicos porque les había pegado y en el colegio la habian denunciado. Se los llevaron 2 años a un instituto. Eso era cuando vivía con el papá de los más chicos. Yo no lo aguantaba a él; él también les pegaba; cuando le dijeron a mi mamá que elija, que si él se iba le devolvían a los chicos, lo siguió teniendo en mi casa. Después él cayó preso por homicidio y ahí se los devolvieron. Hace poco discutí con ella porque le rompió un inflador en la cabeza a mi hermanita. Entonces me echó. Me fui a la casa de mi amiga pero al mes volví porque el nene lloraba que quería estar con mi mamá y lo llevaba y lo dejaba ahí pero no quería estar acá y él allá; entonces volví más por él. Mi mamá me dijo que era recaradura.

La madre no era de ponerle normas: A mí nunca me dio bolilla, ni antes ni ahora.

Cuenta y contó con diversos tipos de apoyo social: Tiene amigas con las que puede hablar sobre algo íntimo o preocupaciones. Con ellas y con la mamá de una de ellas; confío más en ella que en mi mamá. Antes iba a Casa del Adolescente que es del gobierno. Teníamos talleres de carpintería y esas cosas. A algunos les dieron una pasantía para trabajar 16 horas a la semana y ahora estoy esperando que me llamen. Yo elegí administración o telefonía y eso es más difícil de conseguir. Había para peluquería, limpieza, pero yo no quería de limpieza.

De sus estrategias educacionales refiere: Estoy en 6to. año de la escuela técnica (con orientación en Administración de Empresas). En el colegio me va bien, no me llevo materias; nunca repetí.

En cuanto a las estrategias sexuales y reproductivas dice que no quería quedar embarazada: No me lo esperaba. Yo salía con un chico hacía ya 3 años cuando quedé pero me enteré que salía con otra y rompimos. Se había iniciado sexualmente a los 14 años con esa pareja -él tenía 16 años.

Sabía que podía embarazarse: Sabía todo, en la escuela nos pasaron videos sobre las enfermedades, sobre quedar embarazada, anticon- 
ceptivos, sobre alcohol. De que si la mujer tomaba era más fácil perder el conocimiento y que un chico se la lleve a la casa y haga cualquier cosa. Nos dieron sobre el DIU, las pastillas, las inyecciones. Yo usaba preservativos, pero bueno, a veces no lo usábamos.

Cuando se enteró del embarazo estaba contenta pero bueno, no sabía qué pensar. Mi mamá se enojó; quería que me lo saque y yo le decía que no y no. Y ahora es la primera que está detrás de él.

La ginecóloga la derivó a la psicóloga. Con ella hablamos de cómo fue, de cómo me sentía en ese momento y en el momento que me enteré que estaba embarazada. Después me dijo que no fuera más. Después en la escuela me acompañaron; la psicóloga del colegio me ayudaba para ver cómo me iba organizando porque hay un proyecto que trata que las chicas que no dejen porque quedaron embarazadas y nos daban un lugar en Casa Cuna, para que dejáramos a los chicos y pasábamos en los recreos para darle la teta. Actualmente sale con un muchacho pero no es una relación formal. Está tomando pastillas porque a partir de lo que me pasó dije "las voy a tomar igual".

La crianza del hijo le resultó fácil, ya sabía por mis hermanos y mis sobrinos. Lo que le costó fue más que nada para estudiar, porque me distraía mucho, porque tenía que estar con él, pero me fui organizando porque primero lo mandaba acá, a Casa Nido, que cuidan los chicos desde los 45 días hasta los 2 años, y después entró en la guardería de la iglesia; me dieron un papel del colegio como que yo estudiaba, así podía entrar más rápido. El hijo no tuvo problemas de salud. Lo lleva a control cada cuatro meses. El papá reconoció al hijo aunque no lo ve frecuentemente.

Para el sostén económico el papá del nene me da $\$ 100$ (pesos argentinos) por semana y él se encarga de comprarle la ropa y las zapatillas. Ella tiene una beca escolar.

Refiriéndose a las estrategias laborales dice: Trabajé 6 meses en limpieza en una casa de electrodomésticos -de 17 a 22 horas-. Dejé porque cambió de empresa de servicios y no quise ir a otro lado porque acá me quedaba cerca, eran 15 cuadras. 
En cuanto a la organización de su vida cotidiana dice: Voy al colegio a la mañana; me levanto y ya le dejo la ropa preparada para cuando él se levanta. Mi mamá lo viste y lo deja en la guardería y yo lo retiro a la tarde. A menudo hay discusiones con la madre y los hermanos por las tareas domésticas.

En algunos aspectos sus representaciones sociales de género son tradicionales. Considera que el hombre debe mantener a la familia: siempre dicen que el hombre de la casa tiene que mantener a todos, pero no sé, nunca viví así, nosotros nunca tuvimos. Y la mujer debe ocuparse de la casa: Si el hombre trabaja, nosotras tenemos que ocuparnos de la casa. Esas representaciones coexisten con otras que sostienen relaciones más igualitarias: A los chicos tienen que cuidarlos los dos y acompañarlos también, llevarlos al jardin; no siempre la mamá. Y es preferible que una mujer también trabaje para tener sus cosas; no es lindo que querés comprarte algo y tenés que pedirlo. Hubiera preferido tener a su hijo después de terminar la carrera, de tener un buen trabajo y mi casa.

Tiene proyectos definidos: Terminar el colegio y después estaba pensando seguir comercio exterior y despachante de aduana. Nos dieron una charla en el colegio. Pienso trabajar pero no quiero de limpieza porque ya lo hice y no me gusta. Si estoy estudiando quiero algo mejor.

En relación a su situación vital relata que a veces se siente triste porque no lo veo a mi hermano. Está preso por homicidio y hace mucho que no lo veo. A veces se siente aburrida del colegio. Ya me cansó, 6 años siempre lo mismo, la misma rutina. Pero no voy a dejar este año; justo es el último. Dice que su hijo es lo único que me importa. Con su vida está satisfecha.

Entonces, Tamara se crió en una familia conflictiva, en la que se dieron serios episodios de violencia de los padres hacia los hijos y en la cual no había claras normas a seguir. Los principales ingresos de la familia provienen de planes sociales, subsidios y beca. Negoció con el padre del hijo una ayuda económica para sostén del hijo. En cuanto a la educación sexual se muestra claramente la dificultad de instrumentar las medidas preventivas 
a pesar de contar con información adecuada. Contó con el apoyo de diversas instituciones públicas -escuela, centro de salud y casa del adolescente- para organizar su vida cotidiana a partir de su embarazo no previsto -gestión de guardería, orientación vocacional, pasantía-, lo que le permitió continuar sus estudios y pensar en su futuro. A pesar de las relaciones muy conflictivas con la madre, esta la ayuda en algunos aspectos relacionados con la atención del hijo. Cuenta con algunas personas que la apoyan emocionalmente. Tiene proyectos relativamente encaminados respecto a estudiar y trabajar -pero no en cualquier cosa-. El hijo es la fuerza para concretarlos y un amortiguador de las situaciones críticas. Se encuentra satisfecha con su vida.

\section{Análisis comparativo de las familias}

Los testimonios seleccionados muestran la situación de tres mujeres de aproximadamente la misma edad -entre 18 y 20 años-, que vivieron siempre en la villa y que fueron socializadas en estructuras familiares distintas, ninguna de las cuales responden a la familia "nuclear - ideal". Además variaron en cuanto a la calidad de las relaciones familiares y al apoyo de instituciones públicas y comunitarias. Sin embargo las situaciones relevadas son mucho más variadas ya que la edad de las mujeres varió entre los 16 y los 30 años y casi la mitad del total provenían del interior del país o de países limítrofes. Cuando migraron algunas lo hicieron solas, otras con sus parejas, otras para incorporarse a la familia que ya estaba acá. Con esto se quiere señalar que ha de considerarse la heterogeneidad de situaciones en cuanto a la estructura y dinámica familiar.

A continuación, se analizarán comparativamente las características observadas en todas las familias según la calidad de las relaciones familiares y su relación con las estrategias de enfrentamiento de estas mujeres y su satisfacción vital a los fines de tener un panorama más comprehensivo del tema. Se encontraron 15 familias no conflictivas, 8 algo conflictivas, 6 bastante conflictivas 
y 11 muy conflictivas. A los fines de agilizar el análisis se agruparon a las familias no conflictivas y algo conflictivas por un lado y a las bastante y muy conflictivas por otro.

\section{Calidad de las relaciones familiares}

\section{Familia armónica o no conflictiva:}

Las relaciones madre-hija y padre-hija son buenas. A veces aparecen conflictos propios de la etapa de la adolescencia en los que hay diferencias entre los padres y las hijas acerca de temas como los estudios, los permisos para las salidas o los noviazgos, que no son importantes. Se da un buen nivel de comunicación y las hijas recurren a la madre y al padre en caso de necesidad.

- Con mi mamá nos llevábamos, bien, discutíamos como toda madrehija, como todas esas hijas rebeldes pero bueh, éramos compañeras dentro de todo; discusiones comunes como "levántate" o "dame una mano" o "ahora voy", "apúrate".

- Mi mamá siempre me aconsejaba y si por ahí no le gustaba alguna cosa me decía "mirá hija, esto es así y así" y yo ya lo miraba de otra forma el tema; hasta hoy me sirven sus consejos.

- Con mi mamá me llevaba bien, con mi papá también. Le cuento muchas cosas a mi mamá.

Las normas y las formas de control de la conducta de las hijas son responsabilidad de ambos padres y son adecuadas a la edad de las mismas y aceptadas por ellas:

- Nos llevábamos bien porque yo iba a la escuela a la mañana, venía al mediodía, comía, terminaba lo que tenía que hacer del colegio y recién ahí capaz que salía con mis amigas o con mi novio. En mi casa no eran de decir "tenés que hacer esto, aquello". Cada uno ya sabía, estábamos acostumbrados. Cada uno se levantaba a la mañana, hacer la cama, barrer la habitación, desayunar, lavar la taza; desde chiquita mi mamá siempre nos enseñó. Capaz que discutíamos porque un fin de semana yo quería salir y mi mamá decía "no" 
y yo decía " ¿por qué no?" y me decía que "no, y no" y una vez que me decía que no, no se discutía.

Las relaciones entre los padres también fueron buenas, lo cual no excluye las desavenencias y discusiones por diversos motivos que suelen superarse.

En las familias conflictivas las relaciones entre las hijas con ambos padres son muy problemáticas, las hijas se resisten ante normas arbitrarias -no ir nunca a bailes, no ver a amigas/os, no vestirse como quieren, no salir solas a ningún lado-. Las notas bajas e inasistencias, el abandono escolar, las amistades, los noviazgos, las salidas, las tareas domésticas, son motivo de conflicto. Varias hijas fueron echadas o se fugaron.

- Yo me fui de mi casa muchas veces porque mi mamá me insultaba mucho, me maltrataba y quería que me haga cargo de mis hermanos más chicos.

Los padres y madres utilizan técnicas de control muy coercitivas ante comportamientos que no les parecen adecuados, lo cual refuerza los conflictos:

- Mi mamá nos pegaba un cachetazo, gritaba "me tenés podrida", "no te aguanto más".

- Mi mamá se queja de todo. No me dejaba salir a ningún lado. Yo me iba igual; después me pegaba con unas ramas o con el cinto pero igual yo ya salí.

Sin embargo, varias de estas madres coercitivas no ponen normas y las hijas no confían en ellas:

- Nunca le conté nada a mi mamá porque siempre se enojó conmigo; no estuvo cuando yo la necesité, siempre me acuerdo que en mi embarazo ella no me apoyó y siempre hay cosas de atrás que ella me hizo que uno se acuerda.

- En mi casa nunca tuvimos una charla madre-hija, con ella no hablo, no me gusta. 
En estas familias hay algunas chicas que no se criaron con la madre e incluso que no la conocen:

- Hasta los 4 o 5 años vivíamos con ella; después mi papá nos llevó porque ella no nos cuidaba, nos dejaba así no más, nos llenábamos de granitos y todo eso.

En varias de estas familias las relaciones padre-hija (o padrastro-hija) son muy conflictivas:

- Con mi padrastro sufrí mucho; me cagaba a palos. Me encerraba en la pieza, no me daba de comer, era remaldito.

Hay chicas que no conocen al padre y las que no vivieron con la madre tampoco encontraron en el padre quien se hiciera cargo de la función parental:

- $\quad$ Repetí porque no iba mucho a la escuela... porque no tenía ganas de ir, me quedaba en mi casa, vagancia, no más. Yo estaba con mi papá en ese tiempo y él se iba a las 5 de la mañana y volvía a la noche, no se enteraba de nada, si salía, si no salía...

- A mi papá nunca le sentí ese cariño; es como que él es muy él, sólo él, no se preocupa por mí.

En muchas de estas familias se dan situaciones de violencia familiar entre los padres y/o de éstos hacia los hijos/as, por lo que a veces se hicieron denuncias policiales. Las relaciones entre los padres suelen ser muy conflictivas, signadas por el machismo y agravadas por el alcoholismo:

- Ellos siempre se llevaron mal, discusiones, peleas. Se revoleaban las cosas, se agarraban a piñas; mi papá tomaba mucho y nos basureaba a mi mamá, a nosotras. Íbamos de un lado para el otro, a lo de mi tía, a lo de mi abuela; después volvía con él.

Algunos padres han vivido en la misma casa estando separados, aumentando la conflictividad. En estas familias hay varios relatos de familiares que consumen drogas y alcohol, y/o que están presos. 


\section{Trayectorias escolares}

Las mujeres de familias no conflictivas han alcanzado un mayor nivel educativo. Más de los dos tercios de estas mujeres (16) tiene estudios secundarios incompletos o completos, terciarios (sólo 1) o cursan actualmente los últimos años del nivel medio (3). Sólo una no completó los estudios primarios. En estas familias las madres y padres apoyan a las hijas para que estudien, algunos hasta les insisten aunque no siempre logran que éstas lo hagan. Varias de las que se embarazaron cuando estudiaban continuaron los estudios o los retomaron después de haber tenido hijos. Contar con el apoyo de la familia o de la pareja fue crucial.

En cambio casi la mitad de las mujeres de familias conflictivas (7 mujeres) no completaron los estudios primarios, 6 los completaron, 5 no completaron los secundarios y una está cursándolos.

En algunas familias conflictivas no se apoya a las hijas para que sigan estudiando:

- Yo vivía con mi papá; cuando yo tenía 11 años él fallece y me voy a vivir con mi mamá. A los 13 terminé la primaria y ya mi mamá me había conseguido un trabajo. A los 15 me echó.

- Mi mamá nos abandonó y vivía un tiempo con mi papá, un tiempo con una señora que nos cuidaba... Casi no me mandaron a la escuela; leer no sé.

Y en otras familias se presiona tanto a las hijas para que estudien que éstas se rebelan:

- Mi mamá estaba mucho con "si no estudiás no salís", "si no aprobás no te compro tal cosa".

En algunos casos las relaciones familiares conflictivas se entrecruzan con los problemas económicos, para dificultar la continuación de los estudios:

- Cuando iba a hacer 1er. grado fui a vivir en una casa ajena en la ciudad con una señora para ayudarla y que me mandara a la escuela y al otro año me iba a otra casa. A los 14 me fui a lo de mi abuela 
porque mi papá se emborrachaba y le pegaba a mi mamá. Y no quería estar con otra familia porque trabajaba mucho, me maltrataban, me pegaban.

\section{Trayectorias laborales}

En cuanto a las trayectorias laborales se tiene que la mayoría de las mujeres trabajó en algún momento de su vida. Pero mientras que 6 de las mujeres de familias no conflictivas nunca trabajaron -2 porque aún estudian-, sólo 2 de las de familias conflictivas nunca lo hicieron.

Entre las mujeres de familias conflictivas más de dos quintos empezaron a trabajar después del nacimiento del primer hijo y en la mayoría de los casos se debió a que se separaron y debían mantenerse a sí mismas y a sus hijos o para "ayudar al marido". Entre las mujeres de familias no conflictivas, menos de un quinto empezó a trabajar después de tener hijos debido a que deseaban tener independencia económica y "salir de la casa", además de colaborar con el ingreso familiar.

En la actualidad entre las mujeres de familias no conflictivas hay mayor proporción de amas de casa (más de la mitad) y de estudiantes ( 3 de las 4 son de familias no conflictivas) mientras que entre las de familias conflictivas hay mayor proporción de mujeres que trabajan. Pero de estas últimas -9 en total-, 8 tienen trabajos muy precarios -comedores comunitarios con remuneración o sin ella, ayuda a familiares con o sin sueldo, servicio doméstico durante muy pocas horas semanales- $y$ trabajan por estricta necesidad -son mujeres que se separaron-. En cambio varias de las mujeres de familias no conflictivas tienen trabajos formales -en empresas de limpieza, colegios, bares- y trabajan para tener independencia económica, "salir de la casa" además de colaborar con el ingreso familiar. En síntesis, entre las mujeres de familias no conflictivas hay mayor proporción de amas de casa y estudiantes, y entre las de familias conflictivas, mayor proporción de mujeres que trabajan pero en trabajo precarios. 


\section{Trayectorias sexuales, reproductivas y conyugales}

\section{Inicio sexual, primer embarazo y uniones conyugales}

Las adolescentes de familias no conflictivas, en promedio, se iniciaron sexualmente algo más tardíamente (15,2 años) que las de familias conflictivas (14,9 años). Resalta que más de un tercio de las adolescentes de familias conflictivas se iniciaron entre los 12 y 14 años, siendo esa proporción el doble que entre las adolescentes de familias no conflictivas. A su vez estas últimas tuvieron a su primer hijo más tardíamente (17,2 años) que las de familias conflictivas (16,5 años)

Si bien una sola entrevistada menciona que su inicio sexual se produjo por una violación, resalta que ésta pertenece a una familia conflictiva.

Por otra parte la mayoría de las mujeres de ambos grupos se embarazaron estando solteras. Pero la proporción es mayor entre las adolescentes de familias conflictivas. Entre estas algunas se unieron a partir de que se fueron del hogar sin el consentimiento de los padres.

La mayoría de las solteras se unieron estando embarazadas pero proporcionalmente son muchas más las que permanecieron solteras entre las de familias conflictivas -más de un tercio- que entre las de familias no conflictivas (sólo 3 mujeres). Además, entre las mujeres de familias conflictivas algunas se separaron durante el embarazo y otras lo hicieron poco después del parto.

Actualmente la mayoría está unida o casada. Pero entre las mujeres de familias conflictivas es mayor la proporción de separadas y solteras, es decir que les ha sido difícil mantener una relación de pareja. El embarazo fue el motivo de la unión de una buena proporción de las entrevistadas. Pero en las familias conflictivas la unión a veces se produce por la presión de la madre: 
- Mi mamá cuando supo del embarazo me mandó con él porque no quería que me quede ahí tampoco, que él tenía que tener su responsabilidad conmigo y él me llevó.

El embarazo puede determinar una fuga y una unión conyugal por temor a los padres.

- Yo tenía miedo porque me iba a pegar mi papá y entonces le conté a mi novio que quedé embarazada y él me rescató y de ahí me fui de mi casa.

En otros casos las hijas fueron echadas cuando se embarazaron, motivo por el cual se unieron.

- Cuando quedé embarazada mi mamá me dijo que me vaya. Ella decía que él era golpeador, que andaba en la joda. Y sí, usaba droga, tomaba mucho... Y a los meses me separé.

\section{Educación sexual}

Las tres cuartas partes de las entrevistadas sabían que podían quedar embarazadas antes de iniciarse sexualmente. Pero mientras que las tres cuartas partes de las chicas de familias no conflictivas sabían que podían cuidarse para no quedar embarazadas, sólo los dos quintos de las de familias conflictivas lo sabían. Pero en casi todos los casos la información fue muy escasa: sabían de la existencia de los métodos pero no la forma de su uso ni se abordaron otros temas de la sexualidad.

Sin embargo, varias de las madres de las familias no conflictivas fueron más activas y aconsejaron a las hijas consultar por métodos anticonceptivos o las llevaron al médico. En las de familias conflictivas el déficit de información a menudo lo atribuyen a la mala relación con las madres:

- Sabía que podía quedar embarazada por la escuela, veía carteles en la salita por todos lados. Por mi mamá no tanto; nosotras le teníamos miedo y por eso no le preguntábamos nada. 


\section{Uso de métodos anticonceptivos y número de hijos}

Más de la mitad de las mujeres de familias no conflictivas habían utilizado algún método anticonceptivo antes del primer embarazo -generalmente preservativo-, mientras que sólo los dos quintos de las mujeres de familias conflictivas los habían utilizado.

Sin embargo, en casi todos los casos, su uso fue irregular $\mathrm{u}$ ocasional y determinó que más de las tres cuartas partes de las mujeres se embarazaran de su primer hijo sin planearlo. Pero mientras que entre las mujeres de familias conflictivas casi un tercio querían embarazarse, sólo 2 de las familias no conflictivas lo querían. Además, estas mujeres tuvieron un mayor número de hijos.

\section{Aborto}

El aborto tiene un peso considerable como opción ante un embarazo inesperado. Más de la mitad de las entrevistadas hizo una alusión espontánea al tema mencionando que pensaron en el aborto como una opción a concretar o a descartar. Sin embargo esto ha sido mucho más frecuente entre las mujeres de familias conflictivas. Además, muchas de estas últimas fueron presionadas por los padres para abortar o no hacerlo.

\section{Situación vital actual}

Algo más de los dos tercios de las entrevistadas de familias no conflictivas se definen como satisfechas o algo insatisfechas con su vida. Algunas se sienten aburridas por estar siempre en la casa. La mayoría no manifiestan tristeza ni mayores preocupaciones. Sus proyectos se refieren a mejorar la vivienda, mudarse de barrio, trabajar o estudiar en el futuro cuando los chicos crezcan.

Casi la mitad de las mujeres de familias conflictivas declara estar poco o nada satisfechas con sus vidas y todas dicen que muchas veces se sienten tristes o preocupadas: 
- Me siento mal por mi soledad, me siento sola. Hay momentos en que no todo lo ocupan los chicos, más a la noche, no sé si por no tener una pareja estable o de extrañarlo porque yo decidi terminar la relación pero no era que lo había dejado de amar, sino que él no terminaba de dejar a la mujer.

También son varias las que se sienten aburridas por estar todo el día en la casa, por la rutina.

En general no pueden imaginarse el futuro y se sienten desamparadas:

- No tengo ningún plan, no sé; me imagino así lo único que espero es que cambie, que mejore.

- Me gustaría pasear, vagar, no tener responsabilidades. No estoy nada satisfecha con mi vida porque está sufriendo mi hijo. Lo traje al mundo y no tiene padre, ni familia, ni casa; puedo buscar a otra pareja porque el nene a todos mis amigos les tiende los bracitos; cree que es el papá, parece que lo necesita.

La mayoría de las restantes se siente "algo insatisfecha" y sólo 2 se declaran "satisfechas" con su vida. Las que a pesar de situaciones adversas se sienten satisfechas se refieren a los hijos como factores amortiguadores de experiencias negativas y a que pudieron revertir -y no reproducir- la mala relación con la madre o la familia:

- Yo siempre digo que todo eso - la madre la echó- me sirvió cuando fui madre; me dediqué a mis hijas como a mí no se habían dedicado. No quiero para ellas lo que yo pasé.

- Terminar la escuela y trabajar y seguir estudiando es lo único que me importa, y mi hijo.

Los vínculos de apego fuerte en la infancia amortiguarían las experiencias negativas. Una entrevistada de 16 años, con dos hijas, separada, que vive en un cuarto sin baño ni cocina dice:

- Mi mamá se quedó embarazada de chica conmigo; mi abuela la echó y ella anduvo conmigo por la calle y mi mamá luchó por mí y no quería que yo pase todo lo que ella pasó. Cuando tuve a la 
nena ella me regaló esta casa. Y ella dejó a su marido porque él me maltrataba.

Una mención especial merece la situación conyugal actual en relación a la satisfacción con su situación vital. Ya se mencionó que en las familias conflictivas hay una proporción bastante mayor de solteras y separadas que entre las mujeres de familias no conflictivas. Cabe agregar que la mitad de las solteras y los dos tercios de las separadas se encuentran poco o nada satisfechas con su situación vital mientras que menos de un tercio de las unidas se encuentra en esa situación.

\section{Conclusiones}

En un contexto aparentemente homogéneo socioeconómica y espacialmente -como una villa de emergencia- hay una heterogeneidad de modos de vivir y enfrentar la maternidad en la adolescencia y la juventud derivadas de las estructuras de oportunidades de los diferentes contextos familiares -insertos en contextos de pobreza- en los que las mujeres entrevistadas se socializaron que se relacionan con las representaciones sociales de género, los proyectos de vida, la educación sexual, los comportamientos sexuales y reproductivos y la fecundidad, entre otros aspectos.

Puede concluirse que las mujeres de familias no conflictivas alcanzaron mayor nivel educativo, tenían mayor nivel de información sobre sexualidad, hoy trabajan por elección y en empleos formales, pudieron formar y mantener una relación de pareja y controlar su fecundidad en mayor proporción que las mujeres de familias conflictivas. Además, las primeras tienen proyectos positivos para su futuro y se encuentran satisfechas con su situación vital, mientras las segundas manifiestan sentimientos de tristeza, preocupación, aislamiento, soledad, presentan dificultades para proyectarse en el futuro y no están satisfechas con su situación vital.

Se ha mostrado el impacto de las relaciones familiares en las diferencias encontradas y la importancia de lo que Lía Ricón 
(2010), siguiendo a Winnicott, denomina familias suficientemente buenas y que, reelaborando el concepto, pueden caracterizarse como aquellas familias capaces de permitir el desarrollo del niño/a, de interpretar su necesidad y satisfacerla.

La palabra familia deriva del latín "famulus" que significa sirviente o esclavo y fue definida originalmente como "conjunto de los esclavos y criados de una persona". Alude a la protección otorgada por el señor feudal pero también a la servidumbre de sus siervos y esclavos.

Esos conceptos permiten comprender lo que pasa en las familias que no protegen sino que esclavizan e impiden el crecimiento y desarrollo de sus miembros favoreciendo un patrón de sometimiento o de extrema rebelión. Cuando las niñas y adolescentes han vivido en ambientes no contenedores, violentos, en los que sus necesidades no han sido satisfechas, se han sentido abandonadas, se han visto sometidas al poder "sobre" de los padres y madres, es difícil que se desarrollen adecuadamente, lo que se ve reflejado en sus dificultades para enfrentar la maternidad y la vida.

Y es aquí, donde el medio familiar y/o social no es suficientemente bueno, donde el Estado con sus políticas públicas -y las organizaciones comunitarias- deben intervenir para reducir el déficit de amor y cuidado que han padecido. Y donde pueden actuar preventivamente en relación a los propios hijos de estas mujeres, muchos de los cuales no fueron "esperados" o "deseados", ni tuvieron el indispensable lugar en la mente de sus progenitores ni en la estructura social que los va a incorporar.

¿Y por qué hablar de maternidades desde los márgenes? Porque acá se ha tratado de mujeres que han sido madres en la adolescencia, a una edad en la que el imaginario social considera que no están preparadas. Se ha tratado de mujeres que han sido y son madres jóvenes en un contexto de pobreza caracterizada por una deficitaria inserción educacional y laboral. Se ha tratado de mujeres que han vivido y que viven en familias conflictivas, que no 
han sido contenedoras ni suficientemente buenas para satisfacer sus necesidades.

Todo lo cual las ubica en una situación de vulnerabilidad dentro de un proceso de marginalización que puede derivar en la exclusión y "desafiliación" (Castel, 2004). El proceso de marginalización -derivado de la falta de inserción laboral y relacional- implica una carencia de recursos materiales, personales y sociales que determinan estrategias que impiden enfrentar adecuadamente la vida cotidiana y se expresa en la insatisfacción con su situación vital.

Así, a estas madres adolescentes y jóvenes, pertenecientes a una familia en la que prevalecen vínculos conflictivos y que está en situación de pobreza o indigencia, con un bajo nivel educacional y sin un trabajo "decente", cuyas parejas no asumen la paternidad y/o rompe la relación, que no tiene amigas ni apoyos institucionales están en una situación de marginalidad. Sin recursos materiales, personales ni sociales les será difícil cuidar de sí mismas ni de su hijos/as y enfrentar la maternidad.

Sin embargo, la relación no es tan lineal y cuando el Estado, a través de sus instituciones, interviene y pone a disposición de las mujeres los recursos que necesitan, éstas los utilizan y así son varias las mujeres de familias conflictivas -pero también de familias no conflictivas- que están cursando estudios en turnos vespertinos en escuelas cercanas, las que reclaman trabajos "dignos", "con obra social y recibo de sueldo", después de participar en organizaciones comunitarias, que comenzaron a utilizar anticonceptivos, o completaron sus estudios cuando migraron y se instalaron en la villa o que envían a sus hijos a diversas organizaciones de la zona para actividades educativas y recreativas.

¿Y cómo puede intervenir el Estado para garantizar las necesidades y derechos de estas ciudadanas? Por un lado, el Estado tiene una responsabilidad fundamental en desmontar las estructuras patriarcales que generan las condiciones que posibilitan la marginación de este grupo de mujeres y que se incuban tanto en 
las familias como en las instituciones educativas, laborales, religiosas, judiciales y políticas.

En dichas instituciones persisten representaciones sociales que naturalizan las relaciones de género y generacionales desiguales y la violencia hacia los hijos y las mujeres como forma de mantener el poder patriarcal. Para ello es preciso que los distintos agentes del Estado, de acuerdo a una perspectiva de género, revisen las concepciones y prácticas educativas propias del sistema patriarcal, el cuestionamiento de las relaciones de poder entre mujeres y varones y entre padres e hijos y el reconocimiento de la equidad de género y de los derechos de la niñez y adolescencia.

Por otro lado, con un enfoque de ciudadanías diferenciadas que garantice que los derechos de grupos con sus necesidades y derechos específicos -en este caso los de las mujeres-adolescentes- $\mathrm{y}$-jóvenes-pobres-de familias-conflictivas- sean respetados, es decir que se garantice:

- La detección y la atención de las situaciones familiares conflictivas y violentas por parte de las distintas instituciones -escuelas, servicios de salud, organizaciones comunitarias, juzgados-en las que las mujeres interactúan así como su prevención.

- La inclusión de las adolescentes en el sistema educativo y en el mercado de trabajo formal con salarios iguales al de los varones; el acceso a guarderías para los/as hijos/as y a los servicios de salud.

- La redistribución de las tareas domésticas y de cuidado de los hijos que implica una doble jornada laboral.

- La ampliación de las redes sociales y la participación en organizaciones que apunten al empoderamiento de las mujeres y a la democratización de las relaciones familiares.

Estos serían algunas claves para que, en un marco de ciudadanía inclusiva, estas mujeres que viven en los márgenes, que parecen condenadas a seguir siendo pobres, a seguir reconociéndose valiosas únicamente como madres, a seguir sufriendo la 
violencia de género y generacional, a enfrentar la maternidad sin los recursos necesarios y sin apoyo emocional y social, reviertan su situación y gocen plenamente de sus derechos.

\section{Bibliografía}

Bowlby, John (1989): Una base segura. Buenos Aires, Paidós.

Caldeiro, Pilar (2005): Familia y Poder. Buenos Aires, Libros de la Araucaria.

Castel, Robert (2004): La metamorfosis de la cuestión social. Una crónica del asalariado. Buenos Aires, Paidós.

Climent, Graciela; Arias, Diana y col. (1996): “Estilo de vida, imágenes de género y proyecto de vida en adolescentes embarazadas", en Revista Argentina de Ginecología Infanto Juvenil (pp. 47-56), Vol. 3, nº 2.

Climent, Graciela (2003): La maternidad adolescente, una expresión de la cuestión social. Revista Argentina de Sociología Año 1, $\mathrm{n}^{\circ} 1$ (pp. 77-93).

Climent, Graciela; Arias, Diana y Spurio, Cecilia (2000): "Maternidad Adolescente: Un camino hacia la marginación". Cuadernos Médico Sociales $n^{\circ} 77$ (pp. 81-97), Rosario, Centro de Estudios Sanitarios y Sociales/Asociación Médica de Rosario.

Climent, Graciela (2005): “Transformaciones y persistencias en las representaciones sociales y prácticas respecto al trabajo de la mujer". Zona Franca, Año XII, n 14 (pp. 10-22), Rosario, Centro de Estudios Interdisciplinarios sobre las Mujeres, Facultad de Humanidades y Artes. Universidad Nacional de Rosario.

Climent, Graciela (2009): "Voces silencios y gritos: Los significados del embarazo en la adolescencia y los estilos parentales educativos". Revista Argentina de Sociología Año 7, n 12/13, (pp. 186-213), mayo-junio.

De la Vega, María Lucía (s/f): "Ser pobre, joven y madre en tiempos de globalización. Un análisis lingüístico sobre la identidad individual y social en el discurso de adolescentes que han transitado un embarazo en situación de pobreza urbana", en línea: www.lenguas.unc.edu.ar...De\%20 la\%Vega\%Maria\%Lucia.pdf. 
Díaz Veiga, Pura (1987): "Evaluación del apoyo social", en Fernández Ballesteros R., El ambiente. Análisis psicológico (pp. 181203), Madrid, Pirámide.

Di Marco, Graciela (2005): Democratización de las Familias. Buenos Aires, Paidós.

Feijóo, María del Carmen (1993): “La vida cotidiana de las mujeres madres en el marco de la crisis", en Ana María Fernández (comp.) Las mujeres en la imaginación colectiva: Una historia de discriminación y resistencia (pp. 206-250), Buenos Aires, Paidós.

Fernández, Ana María (1994): La mujer de la ilusión. Buenos Aires, Paidós.

Florenzano U., Ramón; Sotomayor C., Patricia; Otava T., Magdalena (2001): "Estudio comparativo del rol de la socialización familiar y factores de personalidad en las farmacodependencias juveniles". Rev. Chil. Pediatr., mayo 2001, vol. 72, n 3 (pp. 219-233), en línea: http://www.scielo.cl/scielo. php?script=sci_arttext\&pid=S037041062001000300006\&lng $=$ es\&nrm $=$ iso

Geldstein, Rosa; Infesta Domínguez, Graciela y Del Pino, Nena (1999): Adquisición de pautas de cuidado de la salud reproductiva en sectores populares de Buenos Aires: la transmisión de madres a hijas (Informe final de investigación), Buenos Aires. CENEP/OMS.

Gogna, Mónica (coordinadora) (2005): Embarazo y maternidad en la adolescencia. Estereotipos, evidencias y propuestas para políticas públicas. Buenos Aires, CEDES/UNICEF.

Horwitz, Nina (1991): "Sistemas de apoyo social y familiar y su medición", en Temas de Salud Mental y Atención Primaria de la Salud, en Florenzano U. et al., Santiago, Facultad de Medicina, Universidad de Chile.

Infesta Domínguez, Graciela (1993): “Características sociodemográficas de las adolescentes madres", en Taller de Investigaciones Sociales en Salud Reproductiva y Sexualidad. Buenos Aires, CEDES-CENEP.

Jadue, Gladys (2003): “Transformaciones familiares en Chile: riesgo creciente para el desarrollo emocional, psicosocial y la educación de los hijos". Estud. Pedagóg. 2003, n²9 (pp. 115-126), en línea: http://www.scielo.cl/scielo.php?script=sci_artte xt\&pid=S071807052003000100008\&lng=es\&nrm=iso. 
Jelín, Elizabeth, 2005: “Las familias latinoamericanas en el marco de las transformaciones globales: Hacia una nueva agenda de políticas públicas". Reunión de Expertos "Políticas hacia las familias, protección e inclusión sociales", CEPAL, Santiago, 28 y 29 de junio 2005, en línea: http: / www.eclac.org/dds / noticias/paginas/0/21520/Jelin.pdf.

Large, Tom (1989): “Some aspects of loneliness in families", Family Process, Vol. 28, n 1 (pp. 25-36).

Louro Bernal, Isabel (2005): "Modelo de salud del grupo familiar". Rev. Cubana Salud Pública. [Online] sep.-dic. S071823762007000200012c. 2005, vol.31, $\mathrm{n}^{\circ}$ 4, en línea: http:/ / scielo.sld.cu/scielo.php?script=sci_arttext\&pid=S0 $86434662005000400011 \& \operatorname{lng}=$ es\&nrm=iso.

Lupica, Carina y Cogliandro, Gisell (2007): Anuario de la maternidad. Las brechas sociales de la maternidad en la Argentina, Buenos Aires, Observatorio de la Maternidad.

Mendieta Cruz, Néstor et al. (1996): Familia de la adolescente embarazada, Bogotá, Fundación Antonio Restrepo Barco/Asociación Salud con Prevención.

Moyano Díaz, Emilio y Ramos Alvarado, Nadia (2007): Bienestar subjetivo: midiendo satisfacción vital, felicidad y salud en población chilena de la Región Maule. Universum, vol.22, n.2, (pp. 177-193), ISSN 0718-2376, en línea: <http:/ /www. scielo.cl/scielo.php?script=sci_arttext\&pid=S07182376200 7000200012\&lng=es\&nrm $=$ iso $>$.

Ortale, Susana (2009): "Programas de salud sexual y reproductiva y maternidad adolescente en La Plata (Buenos Aires, Argentina)". Avá (Posadas). 2009, n 15 en línea: <http://www. scielo.org.ar/scielo.php?script=sci_arttext\&pid=S18511694 2009000200014\&lng=es\&nrm=iso $>$.

Palma, Irma (1991): El embarazo adolescente desde una perspectiva de género. Santiago (mimeo)

Pantelides, Edith; Geldstein, Rosa e Infesta Domínguez, Graciela (1995): Imágenes de género y conducta reproductiva en la adolescencia. Cuaderno 51. Buenos Aires, CENEP.

Pantelides, Edith y Binstock, Georgina (2007): La fecundidad adolescente en la Argentina al comienzo del Siglo XXI. Revista Argentina de Sociología, año 5 n 9 (pp. 24-43). 
Pearlin, Leonard et al. (1981): The stress process, en Journal of Health and Social Behavior, 22 (pp. 337-356).

Pinto Herrera, Florita; Livia Segovia, José; Zegarra Martínez, Vilma; Ortiz Morán, Mafalda; Camacho, Obdulia e Isidoro, Jessica (2002): Trastornos de conducta y funcionamiento familiar en adolescentes, en línea: http://www.unfv.edu.pe/publicaciones_unfv/w\%C3\%B1ay_7/pdf/FLORITA\%20PINTO,\%20PSICOLOGIA.pdf.

Piñero, Laura (1998): Felices por un rato. El embarazo adolescente. Instituto Interdisciplinario de Estudios de Ciencias Humanas. Santa Rosa, Universidad Nacional de La Pampa.

Ricón, Lía (2010): Una familia suficientemente buena. Buenos Aires, Polemos.

Rodrigo, Ma José; Márquez, Ma Luisa; García, Marta; Mendoza, Ramón; Rubio, Antonia; Martínez, Ascensión y Martín, Juan Carlos (2004): "Relaciones padres-hijos y estilos de vida en la adolescencia". Psicothema. Vol. 16, nº 2, (pp. 203-210), en línea: http:/ / www.psicothema.com/pdf/1183.pdf

Torrado, Susana (1982): El enfoque de las estrategias familiares de vida en América Latina. Buenos Aires, Cuadernos del CEUR, n² 2.

Urresti, Marcelo (2000): Informe del Área de Adolescencia. Buenos Aires, UNICEF.

Weinreich, María Lorena e Hidalgo, Carmen Gloria (2004): “Intervención de Salud en Familias de Alto Riesgo Biopsicosocial: Seguimiento a Largo Plazo del Funcionamiento Familiar". Psykhe. vol.13, n 1, (pp. 33-42), en línea: http:/ / www.scielo.cl/scielo.php?script=sci_arttext\&pid=S071822282004000 $100003 \& \operatorname{lng}=\mathrm{es} \& \mathrm{nrm}=\mathrm{iso}$ 